\title{
Paulina Ptak
}

\section{Der Europäische Vollstreckungstitel und das rechtliche Gehör des Schuldners}

Eine Analyse der EuVTVO anhand der deutschen und polnischen Anpassungsvorschriften

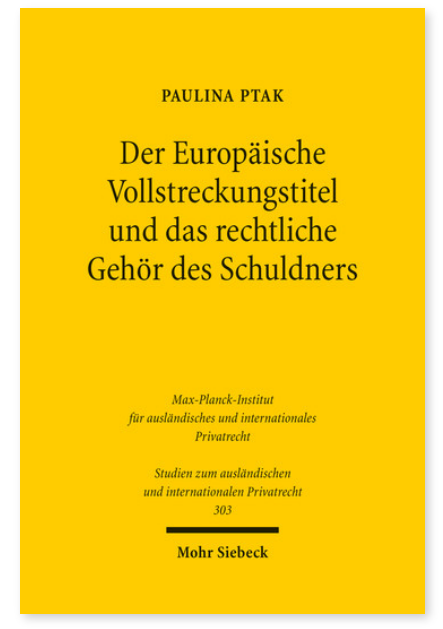

2014. XXII, 266 Seiten. StudIPR 303

ISBN 978-3-16-153056-2

DOI 10.1628/978-3-16-153056-2

eBook PDF 79,00€

ISBN 978-3-16-153022-7

fadengeheftete Broschur 79,00€
Die Europäische Vollstreckungstitelverordnung (EuVTVO) gehört zu den jüngeren Rechtsakten der EU, denen der Regelungsansatz einer einheitlichen und unmittelbaren Geltung von gerichtlichen Entscheidungen in der gesamten EU zugrunde liegt. Die EuVTVO zielt auf diejenigen gerichtlichen Entscheidungen, denen eine 'unbestrittene Forderung' zugrunde liegt. Eine fehlende Verteidigung rechtfertigt allerdings nur dann den Erlass eines europäischen Vollstreckungstitels, wenn der Schuldner eine hinreichende Möglichkeit hatte, zu der Klage gehört zu werden. Die Wahrung des rechtlichen Gehörs ist deswegen die Kernfrage der EuVTVO. Paulina Ptak untersucht die Gewährleistung des rechtlichen Gehörs im Rahmen der EuVTVO und ihrer Anwendung in Deutschland und Polen, zeigt hierfür notwendige Maßgaben auf und arbeitet Lücken in der Gehörswahrung sowie Verletzungen des Prinzips des rechtlichen Gehörs heraus.

Paulina Ptak Geboren 1982; Studium der Rechtswissenschaften in Krakau; Promotion in Heidelberg; 2010-13 Juristin am Europäischen Gerichtshof für Menschenrechte in Straßburg.

Jetzt bestellen:

https://mohrsiebeck.com/buch/der-europaeische-vollstreckungstitel-und-das-rechtliche-gehoer-des-schuldners9783161530562?no_cache=1

order@mohrsiebeck.com

Telefon: $+49(0) 7071-923-17$

Telefax: $+49(0) 7071-51104$ 